\title{
EVALUATION OF THE SHEAR BOND STRENGTH OF TWO TYPES OF ADHESIVE RESIN CEMENTS TO ZIRCONIA AFTER SURFACE TREATMENT USING SILICA COATING
}

\author{
Ahmed Mohamed Ahmed Elsantawi ${ }^{1}$, Mosaad Ali Elgabarouny ${ }^{2}$, Diaa Eldin Saad ${ }^{3}$, \\ Amr Abdelaziz Shebl ${ }^{4}$
}

DOI: $10.21608 / d s u .2020 .14819 .1005$

KEYWORDS

Adhesive resin cement,

Sand blasting,

Silica coating,

Zirconia,

- E-mail address:

madodent@yahool.com

1. Post Graduate Student of Fixed Prosthodontics, Department of Fixed Prosthodontics, Faculty of Dentistry, Suez Canal University

2. Professor of Fixed Prosthodontics-Department of Fixed Prosthodontics, Faculty of Dentistry, Suez Canal University

3. Associate Professor Fixed Prosthodontics, Department of Fixed Prosthodontics, Faculty of Dentistry, Suez Canal University

4. Lecturer in Fixed Prosthodontics, Department of Fixed Prosthodontics, Faculty of Dentistry, Suez Canal University

\section{ABSTRACT}

Aim: to evaluate the shear bond strength of zirconia bonded with two self etch adhesive resin cements PANAVIA F 2.0 and BISTITE ПDC using two surface treatment techniques: sand blasting and silica coating using Cojet system. Materials and Methods: Twenty rectangular samples with dimensions $(14.5 \times 13 \times 3.6 \mathrm{~mm})$ and twenty samples with dimensions $(7.2 \times 6 \times 3.6 \mathrm{~mm})$ were cut from three zirconia ceramic blocks. Sandblasting was done using air blasting machine with $110 \mu \mathrm{m} \mathrm{AL}_{2} \mathrm{O}_{3}$ particles and Silica coating surface treatment was done using Cojet system with $30 \mu \mathrm{m} \mathrm{SiO}{ }_{2}$ particles. Half of the small sandblasted zirconia samples were cemented to half the sand blasted large samples using PANAVIA F 2.0 adhesive resin cement and the rest were cemented using BISTITE ПDC adhesive resin cement. Also, half of the small silica coated zirconia samples were cemented to half the silica coated large samples using both cements. Thermocycling were done for 5000 thermal cycles. The shear bond strength was tested using a computerized universal testing machine. Results: Zirconia specimens cemented with PANAVIA F 2.0 showed higher shear bond strength than specimens cemented with BISTITE ПDC and the zirconia surfaces treated with silica coating and sand blasting surface treatments. Conclusion: PANAVIA F 2.0 resin cement and silica coating surface treatment could be the best cement and surface treatment for zirconia and sand blasting could be a promising alternative surface treatment.

\section{INTRODUCTION}

A need for non-metallic restorative materials with optimal esthetics and characteristics such as biocompatibility, color stability, high wear resistance and low thermal conductivity is often stated as a reason for the use of ceramics in dentistry. Various materials can be used as all-ceramic core materials such as leucite-reinforced ceramics, glassinfiltrated ceramics, lithium disilicate, alumina and zirconia ${ }^{(1)}$.

In clinical dentistry, zirconia is used for construction of orthodontic brackets, posts and cores, implants and implants abutments, crown substructure and frameworks for fixed partial dental prostheses ${ }^{(2)}$.

In addition to its favorable mechanical properties and chemical and dimensional stability, zirconia substructure exhibits good radio-opacity, enhancing radiographic evaluation of marginal integrity 
and detection of recurrent caries. Zirconia offers several advantages including high flexural strength and metal free structure. It also demonstrates excellent optical properties, biocompatibility and low heat conductivity making it one of the most efficient material both for anterior and posterior restoration ${ }^{(3)}$.

Establishing a strong bond with zirconia is only one part of the problem. A more crucial aspect would be maintaining this bond under the influence of fatigue conditions, in presence of saliva and temperature changes for a clinically acceptable time. Several studies investigated the influence of accelerated artificial aging using water storage, thermo-cycling, fatigue and reduction in zirconia resin bond strength was observed.

Application of a silica coat on zirconia, has been used as an experimental surface treatment method. This technology was initially developed for metals to increase bonding ${ }^{(4)}$.

\section{MATERIAL AND METHODS}

Forty rectangular zirconia ceramic samples were cut from three zirconia ceramic blocks using low speed precision saw machine. The samples were cut into two dimensions: Twenty rectangular samples with dimensions $(14.5 \times 13 \times 3.6 \mathrm{~mm})$ and twenty samples with dimensions $(7.2 \times 6 \times 3.6 \mathrm{~mm})$. The twenty sintered zirconia samples with large dimensions were mounted in an acrylic resin designed cubic split mould of $15 \times 15 \times 15 \mathrm{~mm}$ dimensions. Sandblasting was done using air blasting machine with $110 \mu \mathrm{m} \mathrm{AL}_{2} \mathrm{O}_{3}$ particles for 10 samples of each dimensions. The abrasive was applied to the zirconia surface samples at a distance of $10 \mathrm{~mm}$ between the surface of the samples and the blasting tip at 2.5 bar pressure for 20 seconds. Silica coating surface treatment was done using an extra oral blaster with $30 \mu \mathrm{m} \mathrm{SiO}$, particles for the remaining 10 samples of each dimensions. The abrasive was applied perpendicular to the surface of the zirconia surface samples at 3 bar pressure for 15 seconds at a $10 \mathrm{~mm}$ distance.

\section{Cementation of the samples:}

Half of the small sandblasted zirconia samples were cemented to half the sand blasted large samples using PANAVIA F 2.0 (Kuraray medical inc. - Chrome,Umeda, Kita-Ku, Osaka-Japan).

Dual cure adhesive resin cement and the rest were cemented using BISTITE ПDC dual cured adhesive resin cement (5 specimens for each adhesive resin). Also, half of the small silica coated zirconia samples were cemented to half the silica coated large samples using both PANAVIAF 2.0 and BISTITE חDC dual cured adhesive resin cement (5 specimens for each adhesive resin). The small zirconia samples were seated on the center of surface of the large zirconia samples and a standardized load ( $3 \mathrm{~kg}$ ) was applied using a specially designed loading device.

Zirconia specimens were divided into 2 groups according to surface treatment: Group 1: The specimens were sandblasted with $(110 \mu \mathrm{m}) \mathrm{Al}_{2} \mathrm{O}_{3}$ (10 specimens). Group 2: The specimens were silica coated with high purity $(30 \mu \mathrm{m}) \mathrm{SiO}_{2}$ using COJET system(3m ESPE AG. ESPE Platz.Seefield. Germany) (10 specimens). Each group was subdivided into 2 subgroups (5 specimens each) according to the type of adhesive resin cements (n $=5$ ). Subgroup 1P: the specimens were sandblasted and cemented with PANAVIA F2.0 adhesive resin cement (5 Specimens). Subgroup 1B: the specimens were sandblasted and cemented with BISTITE adhesive resin cement (5 Specimens). Subgroup 2P: the specimens were silica coated and cemented with PANAVIA F2.0 adhesive resin cement (5 Specimens). Subgroup 2B: the specimens were silica coated with and cemented with BISTITE adhesive resin cement (5 Specimens). All the cemented specimens were thermocycled between $\left(5-55^{\circ} \mathrm{C}\right)$ 
for 5000 thermal cycles using a thermocycling machine. Each specimen was exposed for 15 seconds at $5^{\circ} \mathrm{C}$ and $55^{\circ} \mathrm{C}$ with 15 seconds interval between each cycle.

\section{Evaluation of shear bond strength of the cement- ed specimens:}

Each cemented specimen was mounted on a universal testing machine (Tira Test 2805, Tira Gmbh, Eisfielder Strabe, Schiakau, Germany) with a load cell of $5 \mathrm{KN}$. The specimen was secured to the lower fixed compartment of testing machine by tightening screws. Shear test was done by compressive mode of a load applied at ceramic cement interface until failure, using a mono-beveled chisel shaped metallic rod attached to the upper movable compartment of testing machine traveling at cross - head of speed of $0.5 \mathrm{~mm} / \mathrm{min}$. The load required for debonding was recorded in Newton. The load at failure was divided by interfacial bonding area to express the bond strength in Mpa.

\section{Statistical analysis:}

The collected data were tabulated and statistically analyzed to evaluate shear bond strength of different adhesives to zirconia. One way analysis of variance (ANOVA) test was used to test the effect of adhesive, surface treatment and their interaction on shear bond strength for all groups.

\section{RESULTS}

\section{Shear bond strength}

The mean shear bond strength of silica-coated zirconia specimens cemented with PANAVIA F2.0 cement (2P) was higher than that of sandblasted zirconia specimens cemented with PANAVIA F2.0 cement (1P) and the difference was significant $(p=0.001)$ as shown in Table (1). The mean shear bond strength of sand blasted zirconia specimens cemented with BISTITE cement (1B) was higher than that of silica-coated zirconia specimens cemented with BISTITE cement (2B) and the difference was significant $(\mathrm{p}=0.019)$ as shown in Table (2). All results were represented in Table (3) and Graph (1).

\section{Mode of failure}

The type and frequency of failure for specimens are presented in (Table 4). The specimens showed two types of failure: adhesive and mixed adhesive/ cohesive failure.

Table (1): Mean and standard deviation (SD) in Mpa of Shear Bond strength of sandblasted and silica coated zirconia specimens cemented with PANAVIA F2.0 cement.

\begin{tabular}{|l|c|c|c|}
\hline & Mean & SD & P-value \\
\hline Sand blasting (1P) & 5.12 & 0.44 & \multirow{2}{*}{$0.001^{*}$} \\
\cline { 1 - 3 } Silica coating (2P) & 8.05 & 0.69 & \\
\hline
\end{tabular}

Table (2): Mean and standard deviation (SD) in Mpa of Shear Bond strength of sandblasted and silica coated zirconia specimens cemented to BISTITE.

\begin{tabular}{|c|c|c|c|}
\hline & Mean & SD & P-value \\
\hline Sand blasting (1B) & 4.63 & 0.71 & \multirow{2}{*}{$0.019^{*}$} \\
\hline Silica coating (2B) & 3.95 & 0.17 & \\
\hline
\end{tabular}

Table (3): Mean and Standard deviation values in Mpa of shear bond strength for all groups:

\begin{tabular}{|c|c|c|c|c|}
\hline & N & Mean & SD & P-value \\
\hline BISTITE (2B) & 5 & 3.95 & 0.17 & \multirow{2}{*}{0} \\
\cline { 1 - 3 } BISTITE (1B) & 5 & 4.63 & 0.71 & \multirow{2}{*}{0.00} \\
\cline { 1 - 3 } PANAVIA (1P) & 5 & 5.12 & 0.44 & \multirow{2}{*}{0.69} \\
\cline { 1 - 3 } PANAVIA (2P) & 5 & 8.05 & \multicolumn{2}{|c}{} \\
\hline
\end{tabular}


Table (4): Mode of failure types:

\begin{tabular}{|l|c|c|}
\hline Cement type & Surface treatment blasting & Silica coating \\
\hline PANAVIA F2.0 & $\bullet 5(\mathrm{AD})$ & $\begin{array}{c}\bullet 3(\mathrm{AD}) \\
\bullet 2(\mathrm{MI})\end{array}$ \\
\hline BISTITE ПDC & $\bullet 5(\mathrm{AD})$ & $\bullet 5(\mathrm{AD})$ \\
\hline
\end{tabular}

AD: Adhesive Failure,

MI: Mixed adhesive/cohesive failure

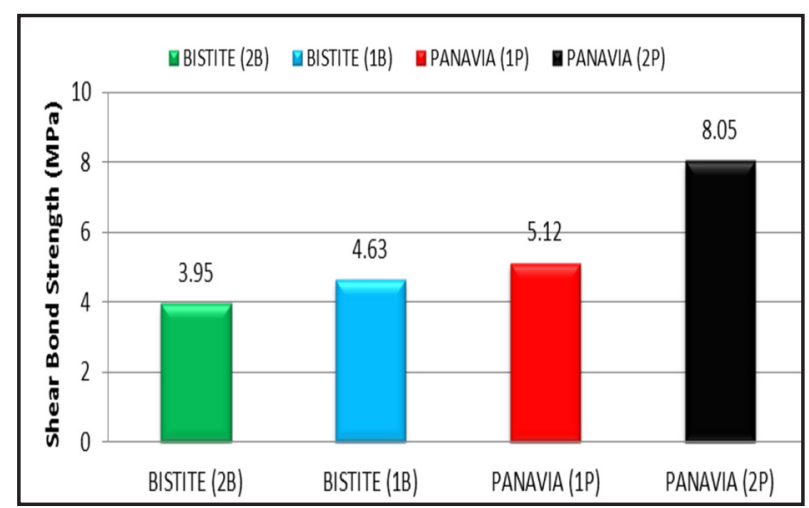

Graph (1): Multiple comparisons of shear bond strength in different techniques (adhesive + surface treatment) of both adhesives

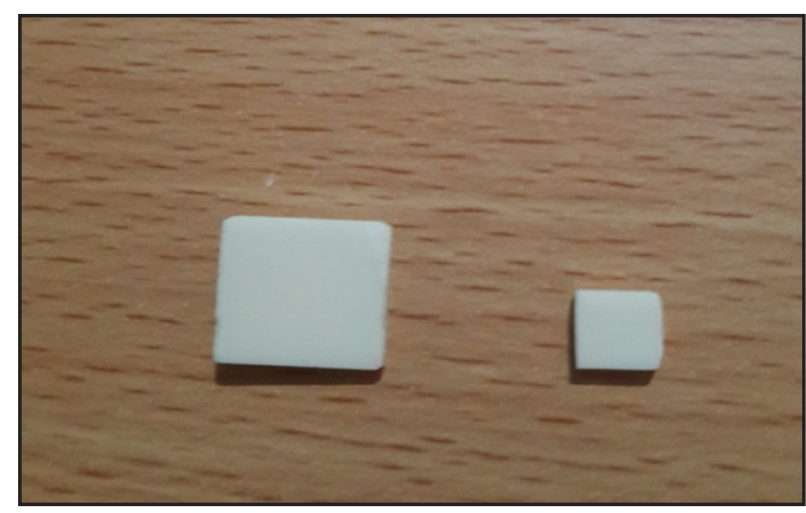

Fig. (1): Two zirconia samples with larg and small dimensions

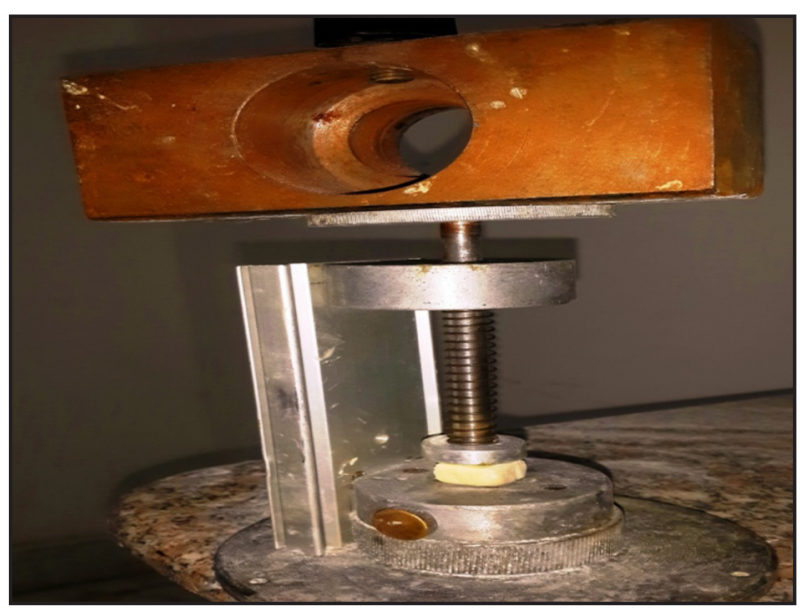

Fig. (2): Specimen cementation using the loading device with load application

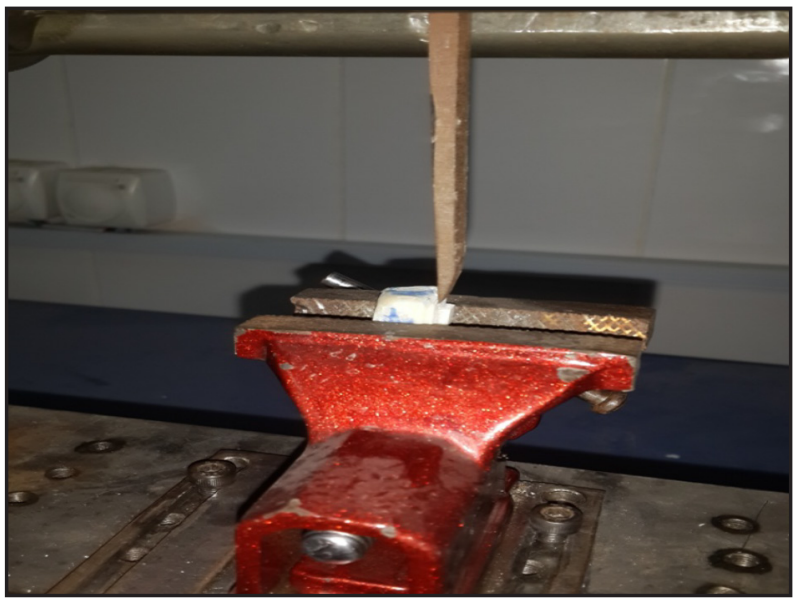

Fig. (3): Load applied at zirconia cement interface

\section{DISCUSSION}

A durable and stable bond between dental tissue, luting cements and ceramics is fundamental for the long-term performance of all ceramic restoration.

In this study it was done using (twin sample technique) as bonding small zirconia samples with dimensions $(6 \times 5 \times 3 \mathrm{~mm})$ to large zirconia samples with dimensions $(13 \times 11 \times 3 \mathrm{~mm})$ which is in the range of sample dimensions of most previous studies to give same change after surface treatment and thermocycling procedure ${ }^{(5,6)}$. 
As zirconia is resistant to traditional ways of surface treatments like acid etching due to its silica and glass-free polycrystalline structure, the current study used sandblasting to increase surface roughness and allow formation of zirconium oxide layer to improve bond strength between zirconia and adhesive resin cement by chemical bond.

Zirconia samples received airborne particle abrasion with $110 \mu \mathrm{m}$ aluminum oxide $\left(\mathrm{Al}_{2} \mathrm{O}_{3}\right)$ particles at 2.5 bar pressure using an air abrasion device for $20 \mathrm{sec}$ from a distance of $10 \mathrm{~mm}$ perpendicularly to the surface ${ }^{(7,8)}$.

The current study selected $110 \mu \mathrm{m}$ as a sample size because big size powder produce higher surface roughness than small size particles $(50 \mu \mathrm{m})$ thereby produce higher micromechanical retention ${ }^{(9,10)}$.

Duration of sandblasting was selected in this study for $10 \mathrm{sec}$ because sandblasting for long period of time causes sharp margins in surface topography that acts as stress points lead to formation and propagations of cracks that can adversely affect the fracture resistance of zirconia ${ }^{(11)}$.

Due to lack of silica in zirconia, silica coating techniques have been explored to utilize the chemical bonding provided by silanization. The use of tribochemical silica coating is a common practice for coating zirconia-based dental ceramics with silica $^{(12)}$.

Using the Cojet system being the most heavily favored commercial products utilized for applying the coating. The tribochemical technique air-abrades zirconia surface with alumina particles that have been coated with silica, embedding/ coating the surface with silica which creates micromechanical retention ${ }^{(13)}$.

Tribochemical silica-coated should be identical and appeared to be pointed in shape. Therefore using Cojet system with $30 \mu \mathrm{m} \mathrm{SiO} 2$ (nano silica) particles is appropriate to produce surface treatment with nano- particles than do with large particles size $^{(14)}$.

Adhesive resin cements are recommended for zirconia restorations to ensure their clinical success as glass ionomer cements have minimal bonding strengths to zirconia and are susceptible to water degradation due to theier chemistry ${ }^{(15)}$.

In the present, two self etch adhesive resin cements were selected: PANAVIA F2.O and BISTITE ПDС. The purpose of selecting these two cements to compare between two self etch adhesive resin cements one of them contains MDP (Panavia F2.O) and to study the effect of thermocycling and surface treatment on their bond strength ${ }^{(16)}$.

Methacryloyloxyde Dihydrogen Phosphateext monomers in self-adhesive cements have been proven to be effective for adhering to the nonsilica-based polycrystalline materials of zirconia. Numerous studies have shown that phosphate monomers are promising chemical agents for improving zirconia bonding ${ }^{(17)}$. The possible mechanism is the ability of phosphate monomers to form chemical bonds with zirconia oxide layer on the surface, and have polymerizable resin terminal end groups (eg, methacrylate), which enable cohesive bonding to appropriate resin cements ${ }^{(18)}$.

In the self-etch technique, no separate etching and rinsing step is needed, that lessens the clinical application time and also the technique sensitivity ${ }^{(19)}$.

Cementation of the samples was done using specially designed device that allowed application of standardized load of $3 \mathrm{~kg}$ for all samples. This load was chosen in many studies to avoid the risk of damaging the zirconia samples ${ }^{(20)}$.

Aging by thermocycling was undertaken in this study to examine the effect of simulated in vivo 
temperature variations on the strength of the bond at the resin/ceramic interface ${ }^{(21)}$.

Shear bond strength not only evaluate the bond strength of adhesive/substrate combination, but also the effectiveness of the surface treatment of the substrate on the bond. It also provides a means of comparing different bonding material ${ }^{(22)}$.

The result of the current study showed that shear bond strength of silica-coated zirconia specimens cemented with PANAVIA F2.0 cement (8.05 Mpa) was higher than that of sandblasted zirconia specimens (5.12 Mpa) and the difference was significant. The higher bond strength values for the silica coated zirconia specimens may be explained as silica coating leave a physically and chemically active outer surface layer (oxide layer) that produced by silica coating more than sand-blasting surface treatment, this silica coating promotes a chemical bonding with phosphate monomer (MDP) which is an ingredient of a composition of PANAVIA $\mathrm{F} 2.0^{(23)}$. This result in agreement with previuos studies that reported silica coating treatment with PANAVIA F2.0 provides a strong and long lasting resin zirconia bond ${ }^{(24)}$.

Also the result of this study recorded that the shear bond strength of sand blasted zirconia specimens cemented with BISTITE ПDC cement (4.63 Mpa) was higher than that of silica-coated zirconia specimens cemented with BISTITE ПDC cement (3.95 Mpa) and the difference was significant. The reason may be due to the Cojet system $(30 \mu \mathrm{m} \mathrm{Sio} 2)$ lead to $\mathrm{Si}$ deposition that might tend to produce a surface with lower roughness and consequently lowers the possibility of mechanical interlocking with BISTITE ПDC adhesive resin cement ${ }^{(25)}$.

Sand blasting surface treatment with $(110 \mu \mathrm{m}$ $\mathrm{AL}_{2} \mathrm{O}_{3}$ ) particles produces more roughness on zirconia surface than silica coating and obtains micromechanical retention on the zirconia surface more than silica coating ${ }^{(26)}$.
Likewise, high viscosity of the BISTITE ПDC causes poor penetration of the cement to the small pores caused by silica coating and good penetration to the large pores caused by sand blasting (27).

This result is in agreement with the finding of several studies which reported that bond strength to zirconia was not improved after silica coating compared to airborne paricle abrasion. However, this result was contradicting to the results of other studies which reported that silica coating improved bond strength to zirconia ceramics compared to sand blasting (28).

According to the results of this study the shear bond strength of sand blasting zirconia specimens cemented with PANAVIA F2.0 cement (5.12 Mpa) was higher than that of sand blasting zirconia specimens cemented with BISTITE ПDC cement $(4.63 \mathrm{Mpa})$ with no statistically significant difference. This high bond of panavia can explained by its content of MDP that produces chemical bond with zirconia. MDP is a functional group with a long hydrophobic chain molecule with two ends. One end has a vinyl group that reacts with the monomer of the resin cement when polymerized. At the other end, hydrophilic phosphate ester groups bond strongly with zirconia oxide layer ${ }^{(29)}$. It was also noticed that also the shear bond strength of silica coated zirconia specimens cemented with PANAVIA F2 0 cement ( $8.05 \mathrm{MPa}$ ) was higher than that of silica-coated zirconia specimens cemented with BISTITE ПDC cement (3.95 MPa) and the difference was significant. This high bond of panavia can be explaine by its content of MDP that produces chemical bond with oxide layer created by silica coating in zirconia surface in addition to mechanical bond created by the roughness of silica coating while BISTITE ПDC cement depends only on mechanical bond created by silica coating on zirconia surface ${ }^{(30)}$.

Tribochemical silica coating is a type of surface treatment in which zirconia surface is abraded with aluminium-oxide particles modified by silica 
and the blasting pressure results in embedding of silica particles on zirconia surface which results in chemical bond between zirconia surface and panavia adhesive resin cement as phosphate ester group of MDP binds directly to zirconia oxide. The efficacy of this surface treatment has been demonstraded in previous studies ${ }^{(31)}$.

Another reason may be due to low viscosity of panavia that increases surface wettability and increases penetration of panavia cement to the small pores that caused by silica coating that leads to high bond strength than BISTITE which is more vis$\operatorname{cous}^{(32)}$.

According to the result of this study it was concluded that there were two types of failure mode of specimens: adhesive failure and mixed adhesive/ cohesive failure. Mixed failure usually associated with better results of shear bond strength values indicated better adhesion between zirconia and adhesive resin cement. So that the results recorded 2 specimens cemented with PANAVIA F2.0 and treated with silica coating revealed mixed failure. This results demonstrated that the cement that achieve chemical bonding (PANAVIA F2.0) and micromechanical retention (silica coating) with zirconia was more effective. The rest of specimens revealed adhesive failure mode indicating lower shear bond strength values. The results obtained in this study were similar to those of previous studies in which authors found a predominence of adhesive failure after shear tests ${ }^{(33)}$.

\section{CONCLUSION}

Within the limitations and conditions of this in vitro study, it could be concluded that:

1. Silica coating surface treatment improved Shear bond strength of PANAVIA F2.0 as the Cojet system promotes surface roughness and provides micromechanical retention and also a chemical bond.
2. Silica coating surface treatment of zirconia specimens showed inferior bond strength for BISTITE ПDC in comparison with the sand blasting surface treatment.

3. Sand blasting surface treatment of zirconia specimens showed high result of shear bond strength than silica coating with BISTITE ПDC as sand blasting with $110 \mu \mathrm{m} \mathrm{AL}_{2} \mathrm{O}_{3}$ obtains micromechanical retention on zirconia surface more than silica coating.

4. Panavia F2.O produced high bond strength in the zirconia specimens treated with silica coating and sand blasting more than BISTITE ПDC.

\section{REFERENCES}

1. Aboushelib M.N., Kleverlaan C.J., Feilzer A.J. Selective infiltration-etching technique for a strong and durable bond of resin cements to zirconia-based materials. J. Prosthet. Dent. 2007;98:379-388.

2. Blatz MB. Long-term clinical success of all ceramic posterior restorations.Quintessence Int.2002; 3:415-426.

3. Atsu SS, Kilikarslan MA, Kukesmen. Effect of ceramic surface treatment on bond strength to adhesive resin.J Prosthet Dent. 2006; 95:430-463.

4. Alvero Della Bona,Maria Borba,Paula Benettic,Dileta Cecchetti. Effect of surface treatment on the bond strength of a zirconia reinforced ceramic to composite resin.Braz Oral Rest. 2007; 21:10-15.

5. Amaral R, Ozcan M, Bottino M. Microtensile bond strength of a resin cement to glass infiltrated zirconia based ceramics. The effect of surface conditioning. Dent Mater. 2006;22: 283-290.

6. Subasi MG and Inan. Evaluation of the topographical surface changes and roughness of zirconia after different surface treatments. Lasers Med Sci. 2012; 27:735-742.

7. Blixt M, Adamczak E, Linden L. Bonding to densely sintered alumina surfaces: effect of sandblasting and silica coating on shear bond strength of luting cement. Int $\mathbf{J}$ Prosthodont. 2000; 13:221-226.

8. Blatz MB, Chiche G, Holst S. Influence of surface treatment and simulated aging on bond strength of luting agents to zirconia. Quintessence Int. 2007; 38:745-753. 
9. Saygili G, Sahmali S. Effect of ceramic surface treatment on the shear bond strengths of two resin luting agents to all-ceramic materials. J Oral Rehabil. 2003;30:758-764.

10. Anand S, Ebenezer AV, Anand N, Rajkumar K, Mahalaxmi S, Srinivasan N. Microshear bond strength evaluation of surface pretreated zirconia ceramic bonded to dentin. Eur J Dent. 2015; 9: 22422-7.

11. Salehi E.A, Heshmat H., Salehi E.M and Kharazifard M.J. In vitro evaluation of the effect of different sandblasting times on the bond strength of feldspathic porcelain to composite resin. J Islamic Dent Ass of Iran (JIDAI). 2013; 25: 22-30.

12. Piwowarczyk A, Lauer HC, Sorensen JA. The shear bond strength between luting cements and zirconia ceramics after two pre-treatment. Oper Dent. 2005;30:382-388.

13. Peutzfeldt A, Asmussen E. Evaluation of a new method of bonding composite resin to metal. Scand J Dent Res. 1988;96:171-177.

14. Chen C, Chen G, Xie H, Dai W, Zhang F. Nanosilica coating for bonding improvements to zirconia. Int $\mathrm{J}$ Nanomrdicine. 2013; 8:4053-4062.

15. Gernhardt CR, Bekes K, Schaller HG. Short-term retentive values of zirconium oxide posts cemented with glass ionomer and resin cement: an in vitro study and a case report. Quintessence Int. 2005 ; 36:593-601.

16. Amaral R, Ozcan M, Valandro LF. Effect of conditioning methods on the microtensile bond strength of phosphate monomer-based cement on zirconia ceramic in dry and aged conditions. J Biomed Mater Res B Appl Biomater. 2008; 85: 1-9.

17. Wegner SM, Kern M. Long-term resin bond strength to zirconia ceramic. J Adhes Dent. 2000 ;2: 139-147.

18. Yoshida K, Tsuo Y, Atsuta M. Bonding of dual-cured resin cement to zirconia ceramic using phosphate acid ester monomer and zirconate coupler. J Biomed Mater Res B Appl Biomater. 2006;77: 28-33 .

19. Perdigao J., May K.N.JR., Wiler A.D.JR., Lopes M. The effect of depth of dentin demineralization on bond strength and morphology of the hybrid layer. Oper Dent. 2000;25: 186-194.

20. Groten M., and Probstar L.: The influence of different cementation modes on the fracture resistance of feldspathic ceramic crowns. Int J Prosthodont. 1997; 10:169-177.
21. Yap A.U., Wang X., Chung S.M.:Comparative hardness and modulus of tooth-colored restorative: Adepth - sensing micro-indentation study. Biomatrials. 2004 ; 63: 2179-2185.

22. Atta M.O.: A Comparative study of the bond strength of chemical and mechanical retention system for direct bonded bridge retainers. (Ph.D.thesis) Faculty of Dentistry. University of London. 1991:1993.

23. Uo M, Sjogren G, Sundh A. Effect of surface condition of dental zirconia ceramic (Denzir) on bonding. Dent Mater J. 2006 ; 25: 626-631.

24. Ozcan M, Alkumuru HN and Gemalmaz D. The effect of surface treatment on the shear bond strength of luting cement to a glass-infiltrated alumina ceramic.Int $\mathrm{J} P$ rosthodont. 2001; 14:335-339.

25. Nothdurft FP, Motter PJ, Pospiech PR. Effect of surface treatment on the initial bond strength of different luting cements to zirconium oxide ceramic. Clin Oral Invest. 2009; 13: 229-235.

26. Valandro L. F., Ozcan M., Bottino M. C.. Bond strength of a resin cement to high-alumina and zirconia-reinforced ceramics: the effect of surface conditioning. J Adhes Dent. 2006; 8: 175-181.

27. De Munk J, Vargas M, Van Landuty K, Hikita K, Lambrech P, Van Meerbeek B. Bonding of an auto-adhesive luting material to enamel and dentin. Dent Mater. 2004; 20:963-971.

28. Luthy H, Loeffel O, Hammerle CH. Effect of thermocycling on bond strength of luting cements to zirconia ceramic. Dent Mater. 2006;22:195-200.

29. Anusavice KJ, Shen C, Rawls HR. Phillips Science of Dental Material.12th ed.ST. Louis Elsevier. 2014;264-6.

30. May LG, Possos SP, Capelli DB, Ozcan M, Bottino MA,Valandro LF. Effect of silica coating combined to a MDP-based primer on the resin bond to Y-TZP ceramic. J Biomed Mater. 2010;95:69-74.

31. Ozcan M. and Vallittu P. K., Effect of surface conditioning methods on the bond strength of luting cement to ceramics. Dent Mater. 2003; 8: 725-31.

32. Tsou Y, Yoshida K, Atsuta M. Effect of alumina-blasting and adhesive primers on bonding between resin luting agent and zirconia ceramics. Dent Mater. 2006;25:669-74.

33. Oyague RC, Monticelli F, Toledano M, Osorio E, Ferrari $\mathrm{M}$, Osorio R. Influence of of surface treatments and resin cement selection on bonding to densely-sintered zirconium-oxide ceramic. Dent Mater. 2009;25:172-9. 